\title{
Pyocine-typing of hospital strains of Pseudomonas
}

\section{pyocyanea}

\author{
J. H. DARRELL AND A. H. WAHBA ${ }^{1}$ \\ From the Department of Bacteriology, Postgraduate Medical School of London, and the Cross-infection \\ Reference Laboratory, Central Public Health Laboratory, Colindale
}

SYNOPSIS A method of typing Pseudomonas pyocyanea is described which makes use of the property of bacteriocine production. The method was applied in an epidemiological study of Ps. pyocyanea infection in a general hospital. It was found that the majority of strains believed on epidemiological grounds to be of common origin were allotted to the same pyocine type.

In the course of this study, Ps. pyocyanea was isolated from 219 patients; 474 strains from 149 of these were typed. There was evidence of cross-infection among patients in a urogenital surgical ward, but in other parts of the hospital there appeared to be little cross-infection. A number of individual instances of auto-infection, possibly arising from the bowel flora, were seen.

"A rational approach to the problem of hospital infection with Gram-negative bacilli has, in the past, been hampered by the lack of adequate typing schemes, for the causative organisms, making epidemiological investigations difficult (Williams, Blowers, Garrod, and Shooter, 1960). Such infections, particularly those with Pseudomonas pyocyanea, are of increasing importance now that there has been some measure of success in controlling staphylococcal infection (Forkner, Frei, Edgcomb, and Utz, 1958; Finland, Jones, and Barnes, 1959; Hodges and de Alvaręz, 1960; Rogers, 1960; Barber, 1961a).

Various investigations have been made into the typing of Ps. pyocyanea by bacteriophage (Gould and McLeod, 1960; Postic and Finland, 1961; Graber, Latta, Vogel, and Brame, 1962). Gould and McLeod's strains were mainly from patients with urinary infections, whilst Graber's strains were predominantly from infected burns. Linton (1960) applied the method of colicine typing to strains of Escherichia coli, but again the investigation was limited to a urological ward. In the investigation to be described, a pyocine typing method was used to study infections with Ps. pyocyanea in a general hospital over a period of one year. The purpose of the investigation was to elucidate the source of hospital infections and the possible route or routes by which they occur. We attempted to include all types of patient and thus to remove the bias

'Present address: Department of Bacteriology, London School of Hygiene and Tropical Medicine, London, W.C.1.

Received for publication 22 August 1963. towards those with urinary infections. No separate unit for patients with burns was available for study in this hospital.

\section{MATERIAL AND METHODS}

STRAINS FOR TYPING Strains of Ps. pyocyanea for typing were obtained from three major sources.

Systematic investigation in a surgical ward Specimens were collected each week from February 1962 to January 1963 inclusive in a 27-bed general surgical ward at a time of maximum activity. They included nasal swabs from all patients and staff, rectal swabs from all patients, swabs from any wounds showing signs of infection, and sputum from patients with productive cóughs. Also, dust swabs were collected each week from 12 predetermined sites in the ward by rubbing a throat swab moistened with broth over one square foot of floor. The blankets on all beds, occupied and unoccupied, were sampled by the press plate technique.

The air was sampled at 12 sites by exposing 3 in. plates for one hour, and also from February to June 1962 at three sites with a Bourdillon slit sampler. This was run for two successive periods each of two minutes, first with a nutrient agar plate and then with a plate of $0.03 \%$ cetrimide agar (Lowbury, 1951; Lowbury and 6 Collins, 1955); the total volume of air sampled at each site was about $100 \mathrm{cu}$. ft.

Phenolphthalein phosphate agar, which was being used to isolate Staph. aureus in a concurrent investigation, proved suitable for the isolation of Ps. pyocyanea. It was used for the nasal swabs, blanket samples, and settle plates. Wound swabs and sputa were plated on blood agar. Dust swabs were inoculated directly onto blood agar, and were enriched in broth before subculture to 
cetrimide agar. Rectal swabs were plated on MacConkey agar; enriched cultures in selenite broth were also subcultured to cetrimide agar.

Infections other than urinary During the six months February to July 1962 strains of Ps. pyocyanea isolated from all patients in the rest of the hospital, with the single exception of urine samples from uncomplicated urinary infections, were submitted for typing. After the first six months, owing to pressure of numbers, only strains from patients from whom two or more strains were isolated could be accepted for typing. Over the whole year Ps. pyocyanea was isolated from 131 separate patients, excluding those with simple urinary infections; strains or sets of strains from 107 of these 131 were typed.

Urinary infections It was our intention to exclude urinary infections from the study. Eleven of the patients with $P s$. pyocyanea infections elsewhere in the body also suffered from urinary infections. Strains from only eight of the 49 instances of uncomplicated urinary infections were included; all were from patients from whom the organism had been isolated on several occasions.

It became apparent, however, that even when most of the urinary infections were excluded, one male urogenital surgical ward provided more infections with $P$ s. pyocyanea than any other ward in the hospital. The strains isolated from this ward will, therefore, be considered separately (Table II).

IDENTIFICATION OF PS. PYOCYANEA Most of the strains isolated showed the classical colonial appearance of Ps. pyocyanea, formed a green diffusible pigment, and smelt strongly of trimethylamine. When this was so, further identification was unnecessary, though the oxidase test (Kovacs, 1956; Steel, 1961) was carried out on all strains. Some strains failed to produce pigment. Gaby and Free (1953) found it to be absent from approximately $4 \%$ of both strains, but from this hospital we have found the proportion to be appreciably higher. Of 1,090 consecutive strains typed in the present and other investigations, $196(18 \%)$ failed to produce pigment on ordinary nutrient media and only one-third of these produced it on special media, including King's medium A (King, Ward, and Raney, 1954). Therefore, all nonfermenting Gram-negative bacilli, whether isolated in the surgical ward or from routine specimens, were also tested in Hugh and Leifson's medium (1953) for the oxidation of glucose. With strains isolated from the environment more profuse growth at $37^{\circ} \mathrm{C}$. than at $22^{\circ} \mathrm{C}$. was considered suggestive of $P$ s. pyocyanea (Mayr-Harting, 1949). All strains typed were first tested for the ability to grow at $42^{\circ} \mathrm{C}$., characteristic of $P s$. pyocyanea (Haynes, 1951; Klinge, 1960).

METHOD OF TYPING Most strains of Ps. pyocyanea produce inhibitory substances called pyocines, which are active upon other strains of $P$ s. pyocyanea. The typing method described here is based on the determination of the range of activity of the pyocines produced by the unknown strain on a set of indicator strains of $P s$. pyocyanea. The technique was developed from that used by Abbott and Shannon (1958) for the colicine-typing of Shigella sonnei. The strain to be typed is first grown as a streak on a solid medium, and the indicator organisms are later applied as a series of transverse streaks (Fig. 1).

Six-inch plates were poured with a deep layer of the typing medium, which consisted of tryptone soya agar (Oxoid) containing $10^{-5}$ molar iodoacetic acid, $0.1 \%$ sodium citrate, and $0.1 \%$ dipotassium hydrogen phosphate. These three chemicals were added to suppress the action of pyocine-inactivating substances produced by the organisms (Wahba, 1963). A central streak, $1 \mathrm{~cm}$. wide, of the strain to be tested was made on the plate. After 24 hours' incubation at $37^{\circ} \mathrm{C}$., the growth was killed by exposure to chloroform vapour for $30 \mathrm{~min}$., scraped off by means of a microscope slide, and the plate again exposed to chloroform vapour for a further 30 minutes After exposure of the plate to the air for one hour, 4-hr. broth cultures of 12 indicator strains were streaked across at right angles to the original growth. As manual streaking was apt to cause irregularities in the inoculum and hence difficulties in reading, an apparatus was devised by Wahba and Lidwell (1963) to provide standard inocula and simplify the procedure. After a

TABLE I

PATTERNS OF INHIBITION OF PROVISIONAL PYOCINE TYPES

Type Indicator Strains

\begin{tabular}{|c|c|c|c|c|c|c|c|c|c|c|c|c|}
\hline & $M 8$ & $B 10$ & $S 17$ & $B 26$ & $B 39$ & $A 52$ & $8 / 39$ & $10 / 55$ & $\mathrm{H} 1180$ & $M 283$ & H323 & $E 826$ \\
\hline $\mathbf{A}$ & + & + & + & + & + & + & + & + & - & + & + & - \\
\hline B & + & + & + & - & + & + & + & - & - & - & + & - \\
\hline C & + & - & + & + & + & + & + & - & - & - & - & + \\
\hline D & + & - & + & - & + & - & + & - & - & - & - & $\div$ \\
\hline$F$ & + & + & - & - & + & + & + & - & - & - & + & $\rightarrow$ \\
\hline $\mathbf{G}$ & - & + & + & - & - & + & - & - & - & - & - & - \\
\hline $\mathbf{H}$ & - & - & - & + & - & - & - & - & - & - & - & - \\
\hline $\mathbf{K}$ & - & + & - & - & + & - & + & - & - & - & + & - \\
\hline L & - & - & - & - & - & + & - & - & - & - & - & - \\
\hline O & - & - & - & - & + & - & + & - & - & - & - & + \\
\hline $\mathbf{P}$ & + & - & - & - & - & - & - & - & - & - & - & - \\
\hline Not typable & - & - & - & - & - & - & - & - & - & - & - & - \\
\hline
\end{tabular}




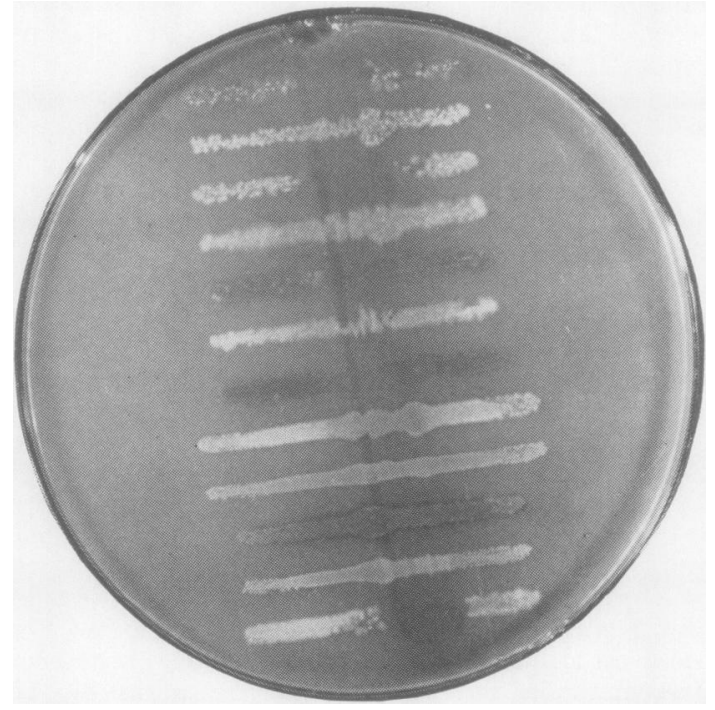

FIG. 1. Typing plate showing a type D strain.

further 16 hours' incubation, zones of inhibition of $2 \mathrm{~cm}$. or more were noted and compared with the provisional type patterns (Fig. 1 and Table I).

Strains producing no inhibition of any indicator strain were recorded as not capable of being typed. In a larger series of 1,090 strains only $7 \cdot 6 \%$ failed to produce pyocine. Occasionally the result was not clear cut, and a better pattern was obtained by plating out the strain and repeating the typing on a new colony. When a strain was very mucoid an attempt was made to select a non-mucoid variant before typing.

\section{RESULTS}

The sources of strains of Ps. pyocyanea typed are shown in Table II. Strains from 149 patients and from the environment of one ward were typed. SURGICAL WARD SURVEY Table III shows the
results of a surgical ward survey.

Rectal swabs yielded Ps. pyocyanea more frequent-露 ly than other types of specimen. It was isolated from $\overrightarrow{0}$ $35(8.2 \%)$ of patients examined. Of these the first specimen examined was positive in 15 , while thec remainder yielded Ps. pyocyanea from the second or subsequent specimens. It was isolated from 10 ? patients more than once, in one instance from five $\overrightarrow{\vec{V}}$ samples, but positive specimens were interspersed $\omega$ with negative ones, and, of 54 specimens yielding Ps. pyocyanea, only 11 did so on direct plating. Dust swabs were the second commonest source of 5 the organism; 30 samples $(4.5 \%)$ were positive. The $\overrightarrow{\vec{r}}$ organism was often isolated from this source when air samples and blanket plates taken at the same time were all negative. There were very few isolations $\vec{\odot}$ from other sources; only three out of 526 patients, + and none of the staff, had positive nasal swabs; two of these patients (cases 1 and 2) had severe clinicals infections with Ps. pyocyanea which was also present in the sputum at the time of its isolation from the nose. These same two patients provided the only $\mathbb{\complement}$ positive wound swabs in the survey. Two other $\Rightarrow$ patients, both chronic bronchitics, also yielded응 Ps. pyocyanea in their sputa on admission. The organism was still present in one on re-admission ao year later but was never isolated from any other site

TABLE II

SOURCE OF STRAINS OF PSEUDOMONAS PYOCYANEA TYPED

$\begin{array}{lcrr}\text { Source of Strains Tested } & \begin{array}{c}\text { No. of Patients Yielding } \\ \text { Ps. pyocyanea in One Year }\end{array} & \begin{array}{l}\text { No of Patients from whom } \\ \text { Strains were Typed }\end{array} & \begin{array}{r}\text { Total No. Strair } \\ \text { General surgical ward }\end{array} \\ \text { Remaining general wards } & 39 & 34 & 70 \\ \text { Urogenital surgical ward } & 124 & 84 & 229 \\ \text { Totals } & 56 & 31 & 175 \\ & 219 & 149 & 474\end{array}$

TABLE III

ISOLATION OF PS. PYOCYANEA FROM A GENERAL SURGICAL WARD DURING ONE YEAR From Patients and Staff

\begin{tabular}{|c|c|c|c|}
\hline \multirow[t]{2}{*}{ Type of Specimen } & \multirow{2}{*}{$\begin{array}{l}\text { Total Persons } \\
\text { Examined }\end{array}$} & \multicolumn{2}{|c|}{ Ps. pyocyanea Isolated } \\
\hline & & Total Patients & $\begin{array}{l}\text { Patients with } \\
\text { Multiple Isolate }\end{array}$ \\
\hline
\end{tabular}

From the Environment

Nose swabs

Patients

Staff

Wound swabs

Sputum

Rectal swabs

$\begin{array}{rr}526 & 3(0.6 \%) \\ 80 & 0 \\ 101 & 2(2.0 \%) \\ 168 & 4(2.4 \%) \\ 426 & 35(8.2 \%)\end{array}$

1
Nil
Nil
Nil
10

Dust swabs
Blanket plate
Air settle plates $(1 \mathrm{hr}$.
Slit samples $(100 \mathrm{cu} . \mathrm{ft}$.

\begin{tabular}{rc} 
Total Samples & $\begin{array}{l}\text { Ps. pyocyanea } \\
\text { Isolated }\end{array}$ \\
\cline { 2 - 2 } & Total Number \\
& \\
660 & $30(4.5 \%)$ \\
1,152 & 0 \\
612 & 0 \\
75 & 0
\end{tabular}

$30(4 \cdot 5 \%)$ 


\section{TABLE IV}

SITE OF ISOLATION OF STRAINS TYPED FROM PATIENTS IN REMAINING GENERAL WARDS AND UROLOGICAL UNIT

General Wards Urological Ward (84) (31)

\begin{tabular}{lcr}
\hline Wound swabs & 34 & 12 \\
Sputum & 24 & 11 \\
Urine & $9^{1}$ & $8^{2}$ \\
Faeces & 20 & 13 \\
Miscellaneous including T/S, & & \\
$\quad$ ear, eye, skin, leg ulcers & 23 & 12
\end{tabular}

${ }^{1}$ Specimens from 12 patients with uncomplicated urinary infections were not tested.

${ }^{2}$ Specimens from 25 patients with uncomplicated urinary infections were not tested.

INFECTIONS IN REMAINING GENERAL AND UROLOGICAL WARDS Table IV shows the sites from which Ps. pyocyanea was isolated from patients in the remaining general wards and urological unit during the period of the surgical ward survey. Strains from the urological ward are considered as a separate group.

DISTRIBUTION OF PYOCINE TYPES Four hundred and seventy-four strains from 149 patients were typed. Table $V$ shows the numbers of patients yielding each type irrespective of the number of occasions on which it was isolated from each patient or the number of sites infected. A change in policy resulted in the exclusion of single specimens in the latter part of the investigation. Therefore, patients have been divided into those from whom a single isolate only has been obtained (88) and those yielding multiple isolates (74). However, considering types A, B, D and those strains which could not be typed separately and after amalgamation of types $\mathrm{C}, \mathrm{F}, \mathrm{G}, \mathrm{H}, \mathrm{K}, \mathrm{L}, \mathrm{O}$, and $P$ to form a single group, the differences between the distribution of types in the two groups of patients are not statistically significant $\left(\chi^{2}=8 \cdot 80\right.$, d.f. $=4, P=0.08$ ), and all patients can be considered as a homogenous series as in line 3 of Table V. The remaining figures (line 4) are included to allow a comparison between the pyocine types found in this hospital and elsewhere, and were from a series of strains from patients in other hospitals typed over the same period as our strains.

Table VI shows the type distribution in the

TABLE V

DISTRIBUTION OF PYOCINE TYPES AMONG STRAINS OF PSEUDOMONAS PYOCYANEA ISOLATED IN A GENERAL HOSPITAL OVER ONE YEAR

Pyocine Type

\begin{tabular}{lllllllllllll}
\hline $\boldsymbol{A}$ & $\boldsymbol{B}$ & $\boldsymbol{C}$ & $\boldsymbol{D}$ & $\boldsymbol{F}$ & $\boldsymbol{G}$ & $\boldsymbol{H}$ & $\boldsymbol{K}$ & $\boldsymbol{L}$ & $\boldsymbol{O}$ & $\boldsymbol{P}$ & Not Typable & Total
\end{tabular}

\section{Patients giving}

Single isolates

Multiple isolates

Total no.

$\%$

Patients from other hospitals

Total no.

${ }^{1}$ One hundred and forty-nine patients, 13 of whom yielded two different pyocine types.

$\begin{array}{clllllllllll}6 & 30 & 1 & 15 & 7 & & - & 1 & 4 & 1 & 7 & 16 \\ 13 & 31 & 1 & 12 & 1 & 1 & - & 1 & 5 & 0 & 3 & 6 \\ 19 & 61 & 2 & 27 & 8 & 1 & - & 2 & 9 & 1 & 10 & 22 \\ 11 \cdot 7 & 37 \cdot 7 & 1 \cdot 2 & 16 \cdot 7 & 4 \cdot 9 & 0.6 & - & 1 \cdot 2 & 5 \cdot 6 & 0.6 & 6 \cdot 2 & 13 \cdot 6 \\ 109 & 174 & 16 & 141 & 74 & 2 & 3 & 4 & 33 & 41 & 23 & 60\end{array}$

88

$162^{1}$

.

$8 \cdot 8$

680

\section{TABLE VI}

NUMBER OF PATIENTS YIELDING EACH PYOCINE TYPE IN A GENERAL SURGICAL WARD AND A UROGENITAL SURGICAL WARD Site Pyocine Type

Urological ward

Remaining general wards

\begin{tabular}{lllllllllllll}
\hline $\boldsymbol{A}$ & $\boldsymbol{B}$ & $\boldsymbol{C}$ & $\boldsymbol{D}$ & $\boldsymbol{F}$ & $\boldsymbol{G}$ & $\boldsymbol{H}$ & $\boldsymbol{K}$ & $\boldsymbol{L}$ & $\boldsymbol{O}$ & $\boldsymbol{P}$ & Not Typable & Total
\end{tabular}

$\begin{array}{rrrrrrrrrrrrr}4 & 5 & 1 & 11 & 1 & - & - & - & 3 & - & 3 & 8 & 36 \\ 3 & 22 & 1 & 3 & 1 & - & - & 1 & - & - & 1 & 2 & 34 \\ 12 & 34 & - & 13 & 6 & 1 & - & 1 & 6 & 1 & 7 & 12 & 93\end{array}$

TABLE VII

NUMBER OF PATIENTS YIELDING EACH TYPE OF PS. PYOCYANEA FROM FOUR MAIN SOURCES

Source Pyocine Type

\begin{tabular}{|c|c|c|c|c|c|c|c|c|c|c|c|c|c|}
\hline & & & & & & & & & & & & \multirow[b]{2}{*}{ Not Typable } & \multirow[b]{2}{*}{ Total } \\
\hline & $\boldsymbol{A}$ & $\boldsymbol{B}$ & $C$ & $D$ & $\boldsymbol{F}$ & $G$ & $\boldsymbol{H}$ & $\boldsymbol{K}$ & $L$ & $O$ & $P$ & & \\
\hline $\begin{array}{l}\text { Wound swabs } \\
\text { Sputum } \\
\text { Urine } \\
\text { Faeces }\end{array}$ & $\begin{array}{r}6 \\
\frac{4}{10}\end{array}$ & $\begin{array}{l}18 \\
16 \\
14 \\
23\end{array}$ & $\frac{1}{1}$ & $\begin{array}{r}8 \\
8 \\
2 \\
12\end{array}$ & $\begin{array}{l}3 \\
2 \\
-1\end{array}$ & $\frac{1}{1}$ & $\bar{z}$ & $\begin{array}{l}2 \\
1 \\
-\end{array}$ & $\begin{array}{l}5 \\
2 \\
1 \\
4\end{array}$ & $\frac{-}{-}$ & $\begin{array}{l}1 \\
\frac{3}{4}\end{array}$ & $\begin{array}{r}3 \\
3 \\
2 \\
13\end{array}$ & $\begin{array}{l}48 \\
40 \\
19 \\
69\end{array}$ \\
\hline
\end{tabular}


various wards while Table VII shows the distribution for samples from four major sites. The total in the last case greatly exceeds the actual number of patients examined as Ps. pyocyanea was frequently isolated from a number of sites in one patient.

ANALYSIS OF TYPING RESULTS FOR CONSISTENCY $P s$. pyocyanea was isolated on more than one occasion from 75 patients. In 62 the same type was isolated on each occasion in from two to 16 cultures. In some cases it was present over periods of up to five months in hospital; in others it was still present on re-admission. Thirteen patients yielded strains of two types; three of these yielded each strain consistently for a period of time, but in only one was one type carried at one site and a different type at another site. Of the remaining 10 patients, six gave, among a number of isolates of one type, a single strain of a different type, while four gave two strains only, each of a different pyocine type. In no case were more than two strains obtained from a single patient.

\section{TABLE VIII}

MULTIPLE ISOLATES SHOWING DEGREE OF CONSISTENCY OF TYPING RESULTS

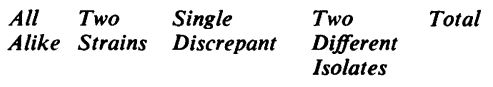

\begin{tabular}{lccccc}
\hline No. patients & 62 & 3 & $6^{1}$ & $4^{2}$ & 75 \\
Total no. strains & 328 & 38 & 26 & 8 & 400 \\
1a. 6 L + 1B. b. 4 A +1 B. & c. $2 A+1$ A. & d. 2 D +1 B. & e. $4 A+1 B$. \\
f. 2 B + 1NT. & & &
\end{tabular}

\section{CASE HISTORIES}

CASE 1 S.A., a managed 56, was admitted for oesophagogastrectomy for carcinoma of the oesophagus.

Ps. pyocyanea was isolated in large numbers from the first rectal swab examined, taken within two days of admission. It was present regularly thereafter in varying amounts, and 17 days later the same type appeared first in the sputum, which had previously been negative for Pseudomonas, and later in the fluid from a thoracic drainage tube.

CASE 2 G.D., a man aged 72, was admitted on 15 February 1962 with carcinoma of the oesophagus. Twelve days after admission a partial gastrectomy and oesophago-gastrostomy were performed. On 8 March 1962 , nine days after the operation, the patient suffered a cardiac arrest. He was resuscitated by closed cardiac massage and a tracheostomy was performed, but he remained deeply unconscious. Two days later $P s$. pyocyanea (type D) was isolated from the tracheostomy wound. Investigation of the side ward in which the patient was being nursed showed relatively gross contamination of the environment. Six of seven dust swabs yielded
Ps. pyocyanea type D, which was also recovered from sweep plates from the bedding, the thermometer jar, and the patient's sink and washing bowl. However, slit sampling at the same time failed to demonstrate the organism in the air. The organisms persisted in the dust for one week, while the patient remained in the ward. He died on 17 March 1962, and after cleansing measures the organism could not be isolated.

CASE 3 A.S., a boy aged 5, was admitted comatose, with bilateral carotid artery thrombosis following a severe upper respiratory infection. A tracheostomy was necessary. Routine rectal swabs yielded Ps. pyocyanea one day before its appearance in the tracheostomy wound and secretions, daily swabs from which had shown no growth from the day the tracheostomy was fashioned. All strains from both sites belonged to the uncommon type $\mathbf{G}$, never before or since isolated in this hospital. Numerous rectal swabs and specimens of stool $\mathrm{\omega}^{\circ}$ yielded Ps. pyocyanea, and it was isolated from the stool even after local treatment had cleared it from the tracheostomy.

\section{DISCUSSION}

Our results suggest that the pattern of infection with Ps. pyocyanea varies in different parts of the hospital. In the general surgical ward infections were not common, and patients' faeces and the dust were the sources of the majority of strains. Lowbury and Fox (1954) isolated Ps. pyocyanea from $94 \%$ of dust samples in a burns ward and $86 \%$ in surgical wards, while in the burns dressing station they found a high incidence of the organism in air samples. In our survey, though dust was a relatively common source, we found only $4.5 \%$ of samples positive and it was unsusual to find more than one or two specimens yielding Ps. pyocyanea at any one time. The organism was rarely isolated on primary plating, suggesting that only a few organisms were present on most swabs. Swabbing was used in preference to the bulk collection of dust used by Lowbury and Fox (1954) as this did not allow the exact site of contamination with Ps. pyocyanea to be determined. One patient only (case 2) produced extensive contamination of his $N$ surroundings and again the total number of organisms was small. In this instance, and throughout the survey, it was impossible to recover Ps. pyocyanea $\underset{\omega}{N}$ from air samples, which suggests that it does not ${ }_{2}$ withstand atmospheric drying (Lowbury and Fox, $\bullet$ 1953). Typing results often related the presence of $\Phi$ the organism in dust to a particular patient, and we $\stackrel{\mathscr{P}}{\rightarrow}$ believe that the presence of Ps. pyocyanea in dust samples was an index of environmental contamination, rather than a serious reservoir of infection, a contention supported by the finding that the $\mathbb{D}$ organism failed to survive normal cleaning measures.

Infection with Ps. pyocyanea in urological wards 
has already been extensively investigated (Pyrah, Goldie, Parsons, and Raper, 1955; Dutton and Ralston, 1957; McLeod, 1958; Gould and McLeod, 1960 ) and this led us initially to exclude uncomplicated urinary infections from our series. However, strains from our urological ward from sources other than urine appeared to show a very different type distribution from those of other wards. Twenty-two $(65 \%)$ of the 34 patients yielding Ps. pyocyanea were infected with type B strains, as compared with five $(14 \%)$ of 36 patients in the surgical ward, and $34(37 \%)$ of 92 patients in the remaining wards. Comparing the urological ward strains with those from other sources, there is a significant excess of type B strains from that ward, suggesting the presence of endemic infection with a particular strain in this unit, as in the wards studied by Gould and McLeod (1960). (For urogenital compared with general surgical ward, $P=0.001$; urogenital $v$. remaining wards, $\mathbf{P}=0.01$ ). Also, as shown in Table VI, strains from wounds, sputa, and faeces show similar proportions of the various types, except for a rather large proportion of non-typable strains from faeces $(19 \%)$. This difference is, however, not significant at the $5 \%$ level $(P=0.1$ to 0.05$)$ and thus specimens from these three sites can be considered as a homogeneous series for comparison with urinary strains, of which 14 of a total of 19 , were type $B$. This shows an undoubted preponderance of this type among the urinary strains $(P=0.01$ to 0.001$)$ and though the series is small it is our impression from an examination of a larger series that type B shows an increased tendency to produce urinary infections.

Figures for the rest of the hospital show no strong evidence of endemic cross-infection. Eleven of the 12 types are represented in the strains isolated. Table IV shows that their occurrence corresponds broadly with their frequency of distribution in other hospitals. The two series are not statistically comparable but some types, notably $\mathrm{A}, \mathrm{B}$, and $\mathrm{D}$, are more frequently isolated than others in both series. Therefore, except in the urological ward, $P$ s. pyocyanea infection is not apparently endemic due to a ward strain. The results indicate short episodes of infection related to sources in a particular patient, such as suggested for staphylococcal infections by Barber and Warren (1962).

Possibly the commonest source of Ps. pyocyanea in non-urinary infections is the faeces, and instances of auto-infection probably arising from this source are described. The proportion of organisms in different faecal specimens varied considerably. Some patients were persistent carriers, often with Ps. pyocyanea present in large numbers in the first specimen examined (case 2). Others had few in the stool only, and those in which it was isolated only some weeks after admission may have ingested strains in the ward, though the probable limited powers of survival of Pseudomonas make this unlikely. Lowbury and Fox (1954) found Ps. pyocyanea in the stools of only $3 \%$ of students but in $20 \%$ of patients in a burns ward. Apparently a large proportion acquired the organism in hospital, but the frequency with which burns become infected with Ps. pyocyanea is well known (Colebrook, Duncan, and Ross, 1948; Jackson, Lowbury, and Topley, 1951; Lowbury and Fox, 1954; Markley, Gurmendi, Chavez, and Bazan, 1957) and it seems likely that much endemic crossinfection occurs in burns units also. Another possible reservoir is the sputum of bronchitic patients (Barber, 1961a and b), though few of these with Pseudomonas in their sputum show dissemination of their own strain to other sites.

Our results show that pyocine typing gives a good distribution of strains between 12 different types. When an uncommon type occurs it is of considerable help in tracing the probable source of an infection and even commonly occurring types afford presumptive evidence of cross-infection. Subtypes of types $\mathrm{A}$ and $\mathrm{B}$ can be distinguished, which should further assist in accurately characterizing strains. The consistent results show that there is no serious tendency to variation in pyocine type among infecting strains, a point of great importance in any typing scheme.

Finally the ability to type an organism by this method is good confirmatory evidence that it is in fact $P$ s. pyocyanea since only $7 \cdot 6 \%$ of strains failed to type by this method.

We wish to thank Dr. Mary Barber and Dr. M. T. Parker for help and encouragement with this work and Dr. A. D. Mitchison for statistical advice. Our thanks are also due to Mrs. J. Filbey, Mr. B. Mepham, Mrs. S. Warren, and Mr. I. F. Rae for technical assistance at various stages, and to Sister Powrie for her cooperation with the ward survey. Finally we are grateful to our clinical colleagues for access to their records and for providing specimens from patients under their care, and to Miss D. CrawfordSmith for the large amount of secretarial work involved.

\section{REFERENCES}

Abbott, J. D., and Shannon, R. (1958). J. clin. Path., 11, 71.

Barber, M. (1961a). Ibid., 14, 2.

- (1961b). Brit. med. J., 1, 1525.

- , and Warren, S. (1962). Lancet, 2, 374.

Colebrook, L., Duncan, J. M., and Ross, W. P. D. (1948). Ibid., 1, 893 Dutton, A. A. C., and Ralston, M. (1957). Ibid., 1, 115.

Finland, M., Jones, W. F. Jr., and Barnes, M. W. (1959). J. Amer. med. Ass., 170, 2188.

Forkner, C. E. Jr., Frei, E., III, Edgcomb, J. H., and Utz, J. P. (1958). Amer. J. Med., 25, 877.

Gaby, W. L., and Free, E. (1953). J. Bact., 65, 746.

Gould, J. C., and McLeod, J. W. (1960). J. Path. Bact., 79, 295.

Graber, C. D., Latta, R., Vogel, E. H. Jr., and Brame, R. (1962). Amer. J. clin. Path., 37, 54. 
Haynes, W. C. (1951). J. gen. Microbiol., 5, 939.

Hodges, R. M., and de Alvarez, R. R. (1960). J. Amer. med. Ass., 173, 1081

Hugh, R., and Leifson, E. (1953). J. Bact., 66, 24.

Jackson, D. M., Lowbury, E. J. L., and Topley, E. (1951). Lancet, 2, 137.

King, E. O., Ward, M. K., and Raney, D. E. (1954). J. Lab. clin. Med., 44, 301

Klinge, K. (1960) J. appl. Bact., 23, 442.

Kovacs, N. (1956). Nature (Lond.), 178, 703.

Linton, K. B. (1960). J. clin. Path., 13, 168.

Lowbury, E. J. L. (1951). Ibid. 4, 66.

-, and Collins, A. G. (1955). Ibid., 8, 47

_, and Fox, J. (1953). J. Hyg. (Lond.), 51, 203.
(1954). Ibid., 52, 403.

McLeod, J. W. (1958). Lancet, 1, 394.

Markley, K., Gurmendi, G., Chavez, P. M., and Bazan, A. (1957). Ann. Surg., 145, 175.

Mayr-Harting, A. (1949). M.D. Thesis, University of Bristol.

Postic, B., and Finland, M. (1961). J. clin. Invest., 40, 2064.

Pyrah, L. N., Goldie, W., Parsons, F. M., and Raper, F. P. (1955). Lancet, $2,314$.

Rogers, K. B. (1960). J. appl. Bact., 23, 533.

Steel, K. J. (1961). J. gen. Microbiol., 25, 297.

Wahba, A. H. (1963). J. Hyg. (Lond.), 61, 431.

- , and Lidwell, O. M. (1963). J. appl. Bact., 26, 246.

Williams, R. E. O., Blowers, R., Garrod, L. P., and Shooter, R. A (1960). In Hospital Infection, p. 96. Lloyd-Luke, London. 